\title{
Procedure Start Relative to Reference Time Point
}

National Cancer Institute

\section{Source}

National Cancer Institute. Procedure Start Relative to Reference Time Point. NCI

Thesaurus. Code C117539.

An indication or description of the start of a procedure in relation to a specific point in time. 